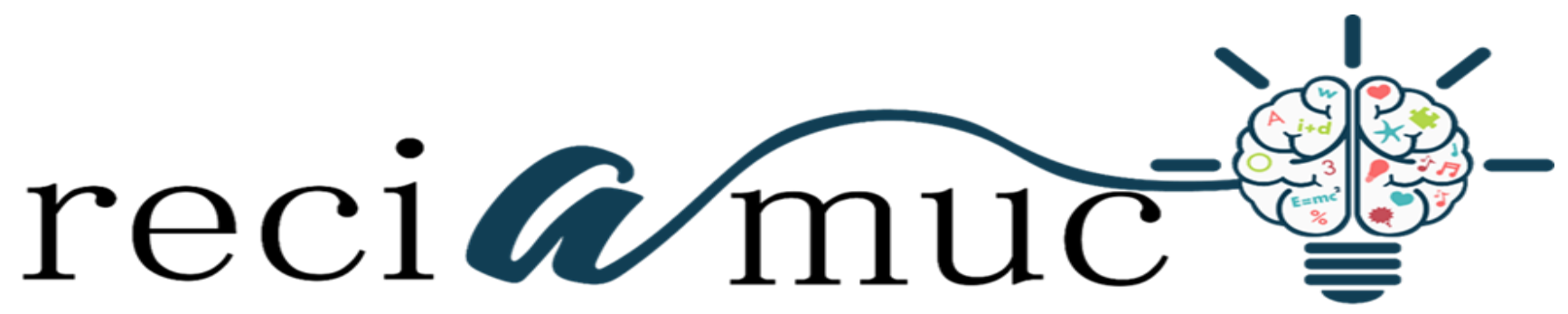

Revista cientifica de investigación actualización del mundo de las ciencias

\author{
Javier Stalin Villagómez Toral a ; Jazmín Del Roció Echeverría Rendón ; Verónica \\ Vanessa Vicuña Terán ${ }^{\mathrm{c}}$; Johnny Correa Michilena ${ }^{\mathrm{d}}$
}

Tratamiento de diarreas en lactantes producidas por rotavirus

Treatment of diarrhea in infant produced by rotavirus

Revista Científica de Investigación actualización del mundo de las Ciencias. Vol. 3 núm., 2, abril, ISSN: 2588-0748, 2018, pp. 265-179

DOI: $10.26820 / \mathrm{reciamuc/3.(2).abril.2019.265-279}$

URL: http://reciamuc.com/index.php/RECIAMUC/article/view/337

Código UNESCO: 3205 Medicina Interna

Tipo de Investigación: Artículo de Revisión

(C) RECIAMUC; Editorial Saberes del Conocimiento, 2019

Recibido: $15 / 01 / 2019$

Aceptado: 07/02/2019

Publicado: 01/04/2019

Correspondencia: javime8590@ outlook.com
a. Médico; Saberes del Conocimiento; Guayaquil, Ecuador; javime8590@ outlook.com
b. Médico; Saberes del Conocimiento; Guayaquil, Ecuador; jazmin_jer16@ hotmail.com
c. Médico; Saberes del Conocimiento; Guayaquil, Ecuador; romi422@live.com
d. Médico; Saberes del Conocimiento; Guayaquil, Ecuador; johnnycorreamichilena@ outlook.com 


\section{Tratamiento de diarreas en lactantes producidas por rotavirus}

Vol. 3, núm. 2., (2019)

Javier Stalin Villagómez Toral; Jazmín Del Roció Echeverría Rendón; Verónica Vanessa Vicuña Terán; Johnny Correa Michilena

\section{RESUMEN}

El rotavirus es un virus que enferma más frecuentemente a niños menores de cinco años en todo el mundo. Uno de sus principales síntomas es la diarrea y su principal complicación es la deshidratación. La mayoría de los lactantes presentan diarrea por rotavirus sobre todo en las primeras etapas de su vida. El objetivo fundamental de este estudio es plasmar el tratamiento básico de la diarrea producida por rotavirus en lactantes. El diseño de investigación que se llevó a cabo es de tipo documental o bibliográfico. El tratamiento de la diarrea por rotavirus en lactantes se orienta a la prevención o tratamiento de su principal complicación: la deshidratación. Este tratamiento se basa en ofrecer solución de rehidratación oral, de acuerdo al grado de deshidratación, y lactancia materna de acuerdo a la condición del niño, así como una adecuada alimentación que se corresponda con la etapa del lactante. Asimismo, el uso de micronutrientes como los suplementos de zinc pueden ayudar en la prevención de la deshidratación. En conclusión, el tratamiento de la diarrea por rotavirus es fundamental para evitar la deshidratación, la cual puede ocurrir muy rápido y tener consecuencias fatales sobre todo en lactantes.

Palabras Claves: Tratamiento, Diarrea, Lactante, Deshidratación, Rotavirus. 


\title{
Tratamiento de diarreas en lactantes producidas por rotavirus
}

Vol. 3, núm. 2., (2019)

Javier Stalin Villagómez Toral; Jazmín Del Roció Echeverría Rendón; Verónica Vanessa Vicuña

Terán; Johnny Correa Michilena

\begin{abstract}
Rotavirus is a virus that makes children under five years of age more frequent worldwide. One of its main symptoms is diarrhea and its main complication is dehydration. Most infants develop rotavirus diarrhea especially in the early stages of their life. The main objective of this study is to capture the basic treatment of diarrhea caused by rotavirus in infants. The research design that was carried out is documentary or bibliographic. The treatment of rotavirus diarrhea in infants is aimed at preventing or treating its main complication: dehydration. This treatment is based on offering oral rehydration solution, according to the degree of dehydration, and breastfeeding according to the condition of the child, as well as adequate feeding that corresponds to the stage of the infant. Also, the use of micronutrients such as zinc supplements can help in the prevention of dehydration. In conclusion, the treatment of rotavirus diarrhea is essential to avoid dehydration, which can occur very quickly and have fatal consequences especially in infants.
\end{abstract}

Key words: Treatment, Diarrhea, Infant, Dehydration, Rotavirus. 


\section{Tratamiento de diarreas en lactantes producidas por rotavirus}

Vol. 3, núm. 2., (2019)

Javier Stalin Villagómez Toral; Jazmín Del Roció Echeverría Rendón; Verónica Vanessa Vicuña Terán; Johnny Correa Michilena

\section{Introducción.}

Los niños constituyen una población vulnerable para innumerables enfermedades en todo el mundo. Las enfermedades más comunes en niños son las gastrointestinales, cuyo síntoma principal es la diarrea.

En los países que se encuentran en vías de desarrollo tres cuartos de la población infantil adquieren el primer episodio de diarrea antes de cumplir los 12 meses de nacido, a diferencia de los países desarrollados donde se presenta de los 2 a los 5 años de edad. Sociedad Española de Pediatría Extrahospitalaria y Atención Primaria (SEPEAP, 2015)

En cuanto a la mortalidad por enfermedades diarreicas, estas ocupan la segunda mayor causa de muerte en infantes menores de cinco años. En cuanto a las estadísticas, estas enfermedades cada año matan a 525.000 niños menores de cinco años. A nivel mundial se originan unos 1.700 millones de casos de enfermedades diarreicas en infantes anualmente. (OMS, 2017)

Las causas de las enfermedades diarreicas son diversas, sin embargo, una de las principales causas se debe a los virus. El rotavirus es la causa más frecuente de diarrea aguda en niños.

"Según las estimaciones de la OMS de 2008, aproximadamente 450.000 niños menores de 5 años de edad mueren cada año por infecciones por rotavirus prevenibles por vacunas; la gran mayoría de estos niños viven en países de bajos recursos”. (Organización Mundial de la Salud, 2015) 


\section{Tratamiento de diarreas en lactantes producidas por rotavirus}

Vol. 3, núm. 2., (2019)

Javier Stalin Villagómez Toral; Jazmín Del Roció Echeverría Rendón; Verónica Vanessa Vicuña Terán; Johnny Correa Michilena

El rotavirus es un virus que causa gastroenteritis, la cual es una enfermedad que se caracteriza por la presencia de diarrea severa, vómitos, fiebre, además de deshidratación. Biblioteca Nacional de Medicina de los Estados Unidos (NLM, 2018)

El síntoma principal de esta enfermedad es la diarrea grave o severa, la cual puede llevar a su complicación mayor: la deshidratación, siendo los niños pequeños la población más afectada. La falta de prevención y tratamiento de la deshidratación puede transformarse en una afección potencialmente mortal. (Mayo Clinic, 2019)

"La mayoría de los lactantes presentan diarrea por rotavirus en las primeras etapas de la vida”. (González, 2017).

Arriola, Lazo, \& Chinchilla (2016) explican que la palabra lactante hace referencia al que mama, es decir, el niño en el período de lactancia. La etapa de lactante, en líneas generales, se extiende desde el nacimiento hasta los dos años de edad. Durante este periodo se le presta especial atención a la alimentación del lactante, la cual comienza con la ingesta exclusiva de leche, ya que su inmadurez solo le permite la utilización de sus reflejos primarios. Posteriormente, de manera gradual se van adicionando otros alimentos. (p. 579)

Esta etapa donde el niño comienza a madurar su sistema nervioso, aparato digestivo y excretor, lo hace especialmente susceptible de presentar problemas gastrointestinales, más frecuentemente diarreas por rotavirus. Esta etapa del niño y la inmadurez de sus sistemas corporales lo ponen en riesgo de que la enfermedad diarreica conlleve con facilidad a otras complicaciones que pueden ser mortales. 


\section{Tratamiento de diarreas en lactantes producidas por rotavirus}

Vol. 3, núm. 2., (2019)

Javier Stalin Villagómez Toral; Jazmín Del Roció Echeverría Rendón; Verónica Vanessa Vicuña Terán; Johnny Correa Michilena

En consecuencia, el tratamiento adecuado para la enfermedad diarreica producida por rotavirus es fundamental para evitar sus consecuencias fatales, de manera especial en la población infantil en donde la rapidez y precisión con que se aplique el tratamiento garantiza que no se presenten complicaciones mayores y el bienestar integral del lactante.

La presente investigación revisa y plasma los tratamientos básicos en el manejo de la diarrea por rotavirus en lactantes, así como las observaciones de las Organizaciones de Salud a nivel internacional y otras instituciones de salud, clasificación de la deshidratación, contraindicaciones al tratamiento y tratamiento de la deshidratación en niños malnutridos.

\section{Materiales y Métodos}

Para el desarrollo de la presente investigación se usaron computadores personales con conexión a internet, con el propósito de exponer acerca del tratamiento de diarreas en lactantes producidos por rotavirus, en virtud de lo cual, el mismo se enmarca en un diseño de investigación documental o bibliográfica.

Esta investigación se limita a la búsqueda y revisión sistemática de material bibliográfico que, por una parte, es accesible mediante el uso de diversas bases de datos, entre las que figuraron: MedlinePlus, PubMed, Biblioteca Virtual de la Salud (BVS), SciELO, Dialnet y ELSEVIER, entre otras; mediante las cuales se sintetizó la mejor evidencia disponible.

Se realizó una búsqueda aleatoria y consecutiva, usando las expresiones "rotavirus en lactantes", "tratamiento de diarrea por rotavirus"; "tratamiento de diarrea en lactantes" y “deshidratación en lactantes”, lo que aproximadamente resultó en más de un centenar de miles de 


\section{Tratamiento de diarreas en lactantes producidas por rotavirus}

Vol. 3, núm. 2., (2019)

Javier Stalin Villagómez Toral; Jazmín Del Roció Echeverría Rendón; Verónica Vanessa Vicuña Terán; Johnny Correa Michilena

registros bibliográficos que luego se fueron filtrando bajo los criterios de idioma español, relevancia, correlación temática y fecha de publicación en los últimos cinco años, sin descartar por tipo de material bibliográfico.

Por último, se le da la correspondiente lectura crítica y análisis de toda esa evidencia científica, lo que resultó consecutiva y consensuadamente en el contenido del presente trabajo.

\section{Resultados}

La diarrea por rotavirus no se puede curar, es decir, carece de un tratamiento médico por cuanto no existen antivirales ni antibióticos contra esta enfermedad, ya que es una enfermedad viral automilitada, tiene un inicio y un final y por lo general es un periodo corto. Su duración es variable, por lo cual, una vez presente la importancia se concentra en evitar complicaciones mientras el virus completa su ciclo.

El periodo de incubación es de 1 a 3 días, la enfermedad inicia con fiebre y vómitos, posteriormente se presenta una diarrea acuosa explosiva. Estos síntomas desaparecen del tercer al séptimo día, pero en algunos casos pueden tardar hasta dos o tres semanas. SEPEAP (2015)

En todo caso, el tratamiento de la diarrea se centra en reponer los fluidos y electrolitos perdidos con el propósito de prevenir su principal complicación: la deshidratación. (Biblioteca Nacional de Medicina de los Estados Unidos, 2018) 


\section{Tratamiento de diarreas en lactantes producidas por rotavirus}

Vol. 3, núm. 2., (2019)

Javier Stalin Villagómez Toral; Jazmín Del Roció Echeverría Rendón; Verónica Vanessa Vicuña Terán; Johnny Correa Michilena

En tal sentido, ante la presencia de diarrea por rotavirus en lactantes, la mayoría de los recursos para su tratamiento estarán orientados a la prevención o el tratamiento de la deshidratación.

\section{Clasificación de la deshidratación.}

Para prescribir el tratamiento de la deshidratación es imprescindible realizar un buen diagnóstico lo antes posible y clasificar el grado de deshidratación del paciente lactante.

Molina (2019) menciona en su trabajo dos criterios para clasificar la deshidratación: según la pérdida de peso y según los niveles del sodio en plasma. En función de la pérdida de peso, la deshidratación se clasifica en deshidratación leve: que corresponde a menos del 5\% de pérdida de peso, la deshidratación moderada: en casos en que el paciente pierde entre el 5 y el 10\% de peso y la deshidratación grave, donde el paciente pierde más de 10\% de peso. En base al balance de agua y solutos la deshidratación se clasifica en hipotónica: con un Na menor a $130 \mathrm{mEq} / \mathrm{L}$., isotónica: donde el valor de Na va de 130 a 150 mEq/L., y la hipertónica: con un Na mayor a 150 mEq/L. (p. 99)

Tratamiento de la diarrea en lactantes

Soluciones de rehidratación oral (SRO).

Las SRO son una mezcla constituida por agua limpia, sal y azúcar. Se caracterizan por ser accesibles económicamente, ya que en todo el mundo tienen un bajo valor. El objetivo de esta 


\section{Tratamiento de diarreas en lactantes producidas por rotavirus}

Vol. 3, núm. 2., (2019)

Javier Stalin Villagómez Toral; Jazmín Del Roció Echeverría Rendón; Verónica Vanessa Vicuña Terán; Johnny Correa Michilena

mezcla es ser absorbida en el intestino delgado y reponer el agua y los electrolitos perdidos por medio de las heces. (OMS, 2017)

La SRO se indica en las deshidrataciones leves y moderadas. En los lactantes de pecho, es recomendable combinarla con tomas de lactancia materna. Está contraindicada en "niños que presentan alteración importante del estado general o del nivel de conciencia y en aquellos que tienen pérdidas de líquidos superiores a las que pueden administrarse por vía oral”. (Molina, 2019, p. 102)

Benéitez \& de Miguel (2015) las SRO clásicas contienen: “90 mmol/1 de Na+, pero, en la actualidad, se recomiendan las denominadas SRO hipotónicas, que contienen aproximadamente $60 \mathrm{mmol} / \mathrm{l}$ de $\mathrm{Na}+$ o las recomendadas por la OMS como soluciones de osmolaridad reducida con $75 \mathrm{mmol} / \mathrm{l}$ de $\mathrm{Na}+$ ”. Las cantidades aconsejadas si no hay deshidratación es de $10 \mathrm{ml} / \mathrm{kg}$ por cada deposición realizada. Para la deshidratación leve, la cantidad aproximada debe ser de 30 a 50 ml/ $\mathrm{kg}$ durante unas 4 horas, además de $10 \mathrm{ml} / \mathrm{kg}$ por cada deposición líquida. En caso de deshidratación moderada, de 75 a 100 ml/kg para compensar el déficit más pérdidas. (p. 54,55)

Antes de recurrir a la vía intravenosa es recomendable la administración de SRO por sonda nasogástrica.

La rehidratación intravenosa se usa cuando la rehidratación oral no es posible. La rehidratación intravenosa rápida está indicada en aquellos casos donde la deshidratación es moderada o grave. Es importante destacar que puede usarse en cualquier tipo de deshidratación con excepción de los casos donde el paciente presente valores extremos de sodio $(<125 \mathrm{mEq} / \mathrm{L}$ o 


\section{Tratamiento de diarreas en lactantes producidas por rotavirus}

Vol. 3, núm. 2., (2019)

Javier Stalin Villagómez Toral; Jazmín Del Roció Echeverría Rendón; Verónica Vanessa Vicuña Terán; Johnny Correa Michilena

$>155 \mathrm{mEq} / \mathrm{L})$. En cuanto a la edad recomendada para este tipo de rehidratación debe ser aplicada a niños mayores de 6 meses. (Molina, 2019, p. 102)

\section{Alimentación.}

\section{Primer semestre}

La malnutrición y las enfermedades diarreicas es un ciclo vicioso que se puede romper continuando la administración de alimentos nutritivos, entre ellos la leche materna, durante los episodios de diarrea. Organización Mundial de la Salud (OMS, 2017)

El lactante alimentado a pecho directo debe mantener la lactancia materna exclusiva, además de la reposición de las pérdidas hidroelectrolíticas. Para el lactante alimentado con fórmulas industriales debe continuarse con el mismo alimento, fraccionado en pequeños volúmenes, pero más frecuentes. Para el caso del lactante alimentado con leche de vaca pasteurizada y diluida, la administración se realiza de la misma forma que la anterior, pequeñas tomas frecuentes. Comité de Nutrición de la Sociedad Uruguaya de Pediatría (CNSUP, 2016)

Segundo semestre Durante el segundo semestre del lactante adicional a las mismas recomendaciones con respecto al alimento lácteo, se debe mantener la alimentación con semisólidos, ya que contienen un buen aporte calórico, ayudan en la digestión y son de fácil acceso. No se deben introducir nuevos alimentos durante el episodio de diarrea, aunque queda a discreción del pediatra tratante según el estado del lactante. No son aconsejables verduras tales como: espinaca, acelga, remolacha, se debe evitar el yogurt dietético o con colorantes, asimismo, el dulce de membrillo no se aconseja por su alto contenido en sacarosa. CNSUP (2016) 


\section{Tratamiento de diarreas en lactantes producidas por rotavirus}

Vol. 3, núm. 2., (2019)

Javier Stalin Villagómez Toral; Jazmín Del Roció Echeverría Rendón; Verónica Vanessa Vicuña Terán; Johnny Correa Michilena

\section{Tercer y cuarto semestre}

En todas las etapas se mantienen las mismas recomendaciones para la alimentación láctea. En casos de intolerancia secundaria a la lactosa, para niños con aceptable estado nutricional, no es imprescindible realimentar con una fórmula deslactosada o leche de soya, en casos de que no se cuente con este tipo de fórmulas, por cuanto el lactante en esta etapa se puede alimentar exclusivamente con sólidos y de esta forma se obtiene un buen aporte calórico y proteico. En esta etapa además se debe incrementar la cantidad de líquidos como el agua, té en cantidades limitadas, agua de arroz, agua de compota, entre otros. En los casos de niños con desnutrición severa o episodios de diarrea reiterados, la alimentación debe realizarse con sólidos, además de una fórmula deslactosada, con la finalidad de garantizar un aporte calórico proteico que favorezca la recuperación de su estado nutricional. CNSUP (2016)

Micronutrientes. Suplementos de zinc.

"Los complementos de zinc reducen un 25\% la duración de los episodios de diarrea y se asocian con una reducción del 30\% del volumen de las heces”. OMS (2017)

La Organización Mundial de la Salud recomienda que las madres, cuidadores, así como el personal sanitario "deben administrar a los niños $20 \mathrm{mg}$ diarios de suplementos de zinc durante 10-14 días (10 mg diarios para los lactantes menores de seis meses)”. OMS (2019) 


\section{Tratamiento de diarreas en lactantes producidas por rotavirus}

Vol. 3, núm. 2., (2019)

Javier Stalin Villagómez Toral; Jazmín Del Roció Echeverría Rendón; Verónica Vanessa Vicuña Terán; Johnny Correa Michilena

\section{Contraindicaciones en el tratamiento.}

Están contraindicadas toda clase de bebidas gaseosas para ser usadas en la rehidratación del lactante, estas poseen bajas concentraciones de sodio y potasio, además de un gran contenido de sacarosa y alta osmolaridad, esto produce distensión abdominal, algunas contienen alto contenido de cafeína, lo cual conlleva a un efecto diurético y en conclusión empeoran la diarrea. Un error común es el uso de gaseosas light, o diet, pensando en que no contienen sacarosa, no obstante, estas bebidas mantienen las otras características señaladas con anterioridad. Por todas estas razones no deben usarse estas bebidas ni para la hidratación, ni para la dilución de las sales de rehidratación oral. Asimismo, es importante que no se usen jugos industriales o polvos para preparar jugos. CNSUP (2016)

Tampoco es conveniente preparar combinaciones especiales de sal y líquido en el hogar. No está indicado evitar que el niño coma, menos si tiene hambre. Usar leche hervida no está indicado. Tampoco se deben usar caldos o sopas salados. Está contraindicado el uso de medicamentos como antidiarreicos, excepto que estén recetados por el pediatra. (Academia Americana de Pediatría, 2019)

\section{Tratamiento en niños malnutridos}

Es importante realizar esta distinción, ya que esta condición hace que la hidratación de estos niños sea más difícil ya que es característico que se dificulte su hidratación normal, además de ser difícil de evaluar. La OMS recomienda para estos casos, en menores de cinco años con malnutrición aguda grave, con deshidratación grave, carentes de estado de choque, la rehidratación 


\section{Tratamiento de diarreas en lactantes producidas por rotavirus}

Vol. 3, núm. 2., (2019)

Javier Stalin Villagómez Toral; Jazmín Del Roció Echeverría Rendón; Verónica Vanessa Vicuña Terán; Johnny Correa Michilena

lenta, ya sea por vía oral o por sonda nasogástrica, administrando ReSoMal (solución de rehidratación para la malnutrición). OMS (2019)

\section{Conclusiones}

La diarrea es uno de los síntomas más importantes de la enfermedad producida por rotavirus que puede llevar a una de sus peores complicaciones: la deshidratación. Esta enfermedad es más frecuente en niños menores de cinco años y especialmente peligrosa en lactantes.

La enfermedad por rotavirus no tiene cura, en tal sentido, todos los esfuerzos, especialmente en lactantes, están orientados a prevenir o tratar la deshidratación.

Las Organizaciones Internacionales que lideran la materia de salud estimulan a los países del mundo a adoptar políticas que satisfagan sus metas a nivel mundial para mantener un mundo más saludable. Los países a través de sus ministerios o instituciones de salud, por lo general, unifican criterios siguiendo los lineamientos internacionales y elaboran sus guías de prácticas clínicas que permiten reducir las tasas de morbilidad y por mortalidad por enfermedades.

En el caso de las enfermedades diarreicas por rotavirus en lactantes, a pesar que de un país a otro pueda variar mínimamente su tratamiento, las bases generales son las mismas: antes de que se presente la deshidratación el tratamiento consiste en ofrecer solución de rehidratación oral después de cada deposición, además de la nutrición normal según la edad del lactante y la condición que presente. 


\section{Tratamiento de diarreas en lactantes producidas por rotavirus}

Vol. 3, núm. 2., (2019)

Javier Stalin Villagómez Toral; Jazmín Del Roció Echeverría Rendón; Verónica Vanessa Vicuña Terán; Johnny Correa Michilena

La lactancia materna, siendo el alimento más seguro del lactante, no debe ser suspendido en el tratamiento ni de prevención, ni de tratamiento de la deshidratación.

Una vez presente la deshidratación es importante, en primer lugar, clasificarla y detectar cualquier otra condición de salud del lactante antes de indicar el tratamiento de rehidratación a seguir. La rehidratación se realiza con soluciones de rehidratación oral y las vías de administración pueden ser oral, nasofaríngea o intravenosa.

Otro aspecto del tratamiento es la nutrición del niño durante los episodios diarreicos, la que, por lo general, no debe ser suspendida, sólo se deben evitar alimentos o líquidos que complican o empeoran la enfermedad.

Por último, el uso de suplementos de zinc puede resultar beneficioso para la reducción de los episodios y el volumen de las deposiciones.

\section{Referencias Bibliográficas}

Academia Americana de Pediatría. (2019). healthychildren.org. Recuperado el 29 de Julio de 2019, de https://www.healthychildren.org/spanish/healthissues/conditions/abdominal/paginas/diarrhea.aspx

Arriola, A., Lazo, B., \& Chinchilla, J. (septiembre de 2016). Fundamentos sobre Alimentación del lactante sano. Acta Pediátrica Hondureña, 7(1), 579-586.

Benéitez, A., \& de Miguel, F. (2015). Gastroenteritis aguda. Pediatría Integral, 19(1), 51-57. Recuperado el 28 de Julio de 2019, de https://www.pediatriaintegral.es/wpcontent/uploads/2015/xix01/05/n1-051-057_Ana\%20Beneitez-int.pdf

Biblioteca Nacional de Medicina de los Estados Unidos. (18 de septiembre de 2018). MedlinePlus. Recuperado el 11 de abril de 2019, de https://medlineplus.gov/spanish/diarrhea.html 


\section{Tratamiento de diarreas en lactantes producidas por rotavirus}

Vol. 3, núm. 2., (2019)

Javier Stalin Villagómez Toral; Jazmín Del Roció Echeverría Rendón; Verónica Vanessa Vicuña Terán; Johnny Correa Michilena

CNSUP. (Julio de 2016). sup.org.uy. Recuperado el 29 de Julio de 2019, de https://www.sup.org.uy/wp-content/uploads/2016/07/Alimentacion-del-Lactante-condiarrea-aguda.pdf

González, E. (26 de junio de 2017). Diarrea aguda, prolongada y persistente en niños y su diferencia de la diarrea crónica. Comunicación Biomédica, 21(9), 2047-2060. Recuperado el 26 de Julio de 2019, de http://medisan.sld.cu/index.php/san/article/view/1681/html

Mayo Clinic. (20 de junio de 2019). mayoclinic.org. Recuperado el 26 de Julio de 2019, de https://www.mayoclinic.org/es-es/diseases-conditions/rotavirus/symptoms-causes/syc20351300

Molina, J. (2019). Deshidratación. Rehidratación oral y nuevas pautas de rehidratación parenteral. Pediatría Integral, 23(2), 98-105.

NLM. (13 de septiembre de 2018). MedlinePlus. Recuperado el 26 de Julio de 2019, de https://medlineplus.gov/spanish/rotavirusinfections.html

OMS. (02 de mayo de 2017). who.int. Recuperado el 25 de Julio de 2019, de https://www.who.int/es/news-room/fact-sheets/detail/diarrhoeal-disease

Organización Mundial de la Salud. (13 de abril de 2015). who.int. Recuperado el 26 de Julio de 2019, de https://www.who.int/immunization/diseases/rotavirus/es/

Organización Mundial de la Salud. (05 de abril de 2019). who.int. Recuperado el 30 de julio de 2019, de https://www.who.int/elena/titles/zinc_diarrhoea/es/

Organización Mundial de la Salud. (05 de abril de 2019). who.int. Recuperado el 29 de Julio de 2019, de https://www.who.int/elena/titles/dehydration_sam/es/

SEPEAP. (21 de Julio de 2015). Sociedad Española de Pediatría Extrahospitalaria y Atención Primaria. Recuperado el 27 de Julio de 2019, de https://sepeap.org/posicion-de-laorganizacion-mundial-de-la-salud-oms-en-la-vacuna-del-rotavirus/

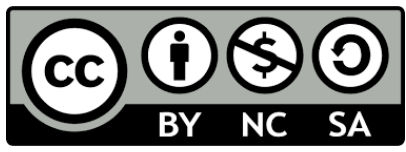

RECONOCIMIENTO-NOCOMERCIAL-COMPARTIRIGUAL

CC BY-NC-SA

ESTA LICENCIA PERMITE A OTROS ENTREMEZCLAR, AJUSTAR Y CONSTRUIR A PARTIR DE SU OBRA CON FINES NO

COMERCIALES, SIEMPRE Y CUANDO LE RECONOZCAN LA AUTORÍA Y SUS NUEVAS CREACIONES ESTÉN BAJO UNA LICENCIA CON LOS MISMOS TÉRMINOS. 